\title{
A RATIONALE FOR IMPROVING STUDENT RECORDER CONTROLS IN LANGUAGE LABORATORIES OF THE LEVEL III TYPE
}

by Jean $R$. Theuma

A recent survey of the recording facilities intended for student use in language laboratories of the audio-active-record type reveals a lack of agreement among manufacturers as to the purpose of such equipment. On the other hand, educators themselves may have failed to stipulate and advertise the kind of learning experiences which they expected these labs to provide. As a result, the hardware controls put at the student's disposal come in all sorts of shapes, sizes, and configurations, none especially designed to facilitate the learning process during laboratory practice.

If the advantages of equipping a booth with a tape recorder ${ }^{1}$ are primarily to give the student full control over his learning materials and an opportunity to record his performance, the criterion in evaluating a lab so equipped should be the ease with which such operations can be performed.

Let us break down into its components-pedagogical and mechanical-a likely unit of lab work:

\begin{tabular}{|c||c|}
\hline \multicolumn{1}{|c|}{ THE STUDENT } & THE RECORDER \\
\hline $\begin{array}{l}\text { Learner's } 1 \text { st attempt: records } \\
\text { his performance }\end{array}$ & PLAY/RECORD \\
\hline $\begin{array}{l}\text { immediately compares his performance } \\
\text { with model }\end{array}$ & STOP \\
& REWIND \\
& STOP \\
PLAY \\
\hline Learner's $2 n d$ attempt: re-records & STOP \\
himself & REWIND \\
& STOP \\
& PLAY/RECORD \\
\hline immediately evaluates his progress & STOP \\
& REWIND \\
& STOP \\
& PLAY \\
\hline
\end{tabular}

1 For the purpose of this article, whether the student recorders are installed in booths or on remore racks is irrelevant. 
It should be noted that: 1) the learning cycle described above relates to the practice of a single response, 2) up to 15 changes in recorder functions may be needed, and 3 ) it is not uncommon for 50 such work units to make up an average lab assignment. This means, in terms of hardware manipulation, that a student might have to push, hold, or turn some sort of a switch 750 times during the course of his lab session!

Have student recorder controls ever been designed with this requisites in mind? I have yet to visit a lab installation where the student does not have to waste a considerable amount of attention and energy to operate his recorder. In most cases, one has first to look in order to locate the controls, then think because of their haphazard or illogical arrangement. Quite often, both hands are needed to go into the record mode. After a few attempts, the student decides that to play back a difficult passage or listen to his immediate recording is simply too much bother.

The functional aspect of any item of lab equipment would certainly improve if manufacturers were wont to send their staff around asking questions such as, "What is it exactly you wish your students to accomplish in the lab?" It would help also if, occasionally, design engineers were actually to enter a lab, borrow a tape, sit in a booth and put themselves in the student's shoes. At the Language Laboratories of the University of Hawaii, however, we decided to go ahead and design our own controls. In fact, it only took an able technician of ours a couple of months to build a working model of the panel shown below.

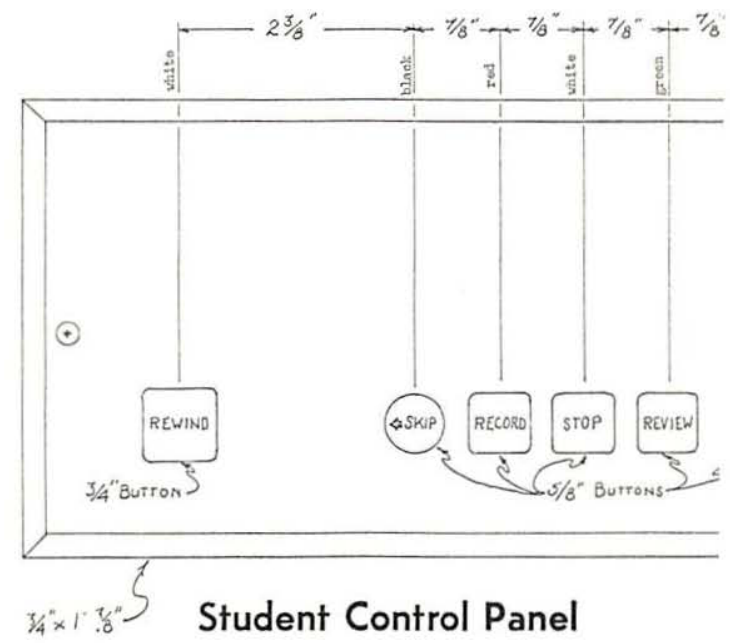


The shape, size, color and arrangement of the 6 push-buttons making up this Control Panel have been carefully tested for maximum simplicity and ease of operation. The REWIND button, for instance, is out of the way because it's likely to be used only once-at the end of the session. SKIP buttons are intentionally different so as to be recognized by feel. But the most crucial feature, by far, is the juxtaposition of the SKIPBACK and RECORD buttons which makes child's play of the mechanical aspects of going over small units of taped materials again and again until mastery is achieved. Indeed, by studying the functional roles of these two controls in the chart below, it will be seen that a student could be blindfolded and still operate his recorder through an entire lab session by using the tips of only two fingers.

\begin{tabular}{|c|c|c|c|}
\hline REVIEY & when touched once & ceck goes into PLAY function & both tracks are in playoack function \\
\hline RECORD & when touched once & $\begin{array}{l}\text { 1. deck goes into PLAY function } \\
\text { 2. RECORD mode siral taneously }\end{array}$ & $\begin{array}{l}\text { master track is in playback function } \\
\text { studest track is in erase/record func:ion }\end{array}$ \\
\hline STOP & when touched once & $\begin{array}{l}\text { 1. deck STOPS } \\
\text { 2. Drops out of RECORD frode }\end{array}$ & \\
\hline REMINO & when touched once & $\begin{array}{l}\text { 1. deck STOPS (if in motion) } \\
\text { 2. drops out of RECORD node } \\
\text { 3. REWINDS all the Way } \\
\text { 4. goes back to STOP position }\end{array}$ & \\
\hline \multirow[t]{2}{*}{ SXIP BACK } & \multirow[t]{2}{*}{ while theld depressed } & $\begin{array}{l}\text { 1. deck STOPS } \\
\text { 2. drops out of RECORD noce } \\
\text { 3. REuINOS as long as switch is } \\
\text { held down }\end{array}$ & \\
\hline & & $\begin{array}{l}\text { 4. STOPS rewinding } \\
\text { 5. drops back instantly into PLaY }\end{array}$ & both tracks are in playback function \\
\hline \multirow{2}{*}{$\begin{array}{l}\text { SXIP } \\
\text { FORNARO }\end{array}$} & \multirow[t]{2}{*}{ while held depressed } & $\begin{array}{l}\text { 1. deck drops out of RECORD soce } \\
\text { 2. gocs FAST FORLARD as long as switeh } \\
\text { is held down }\end{array}$ & \multirow[b]{2}{*}{ both tracks are in playback function } \\
\hline & & 3. drops back instantiy into PLAY & \\
\hline
\end{tabular}

\section{Student Controls Functions}

A word of caution regarding the SKIPBACK control: its rewind speed should not be more than twice its forward speed if precise positioning is to be feasible while repeating short segments of tape and if earphone blasting is to be avoided.

Another concern of ours has been the location of the Control Panel in relation to the student's sitting posture. The right place for a panel should be wherever the student's arm, hand and fingers can assume a normal and relaxed position while manipulating the controls, so as to induce an automatic use of them.

Of course, more research is needed in both the pedagogical and the mechanical aspects of language lab instruction. Unfortunately, experts in these two fields usually work and live in different worlds. If our attempt to bridge the gap is to be worth anything, it should be to encourage both lab makers and lab users to develop a genuine interest in each other. 